\title{
COMPORTAMIENTO A TRACCIÓN DE CEMENTOS REFORZADOS CON FIBRAS DE VIDRIO
}

\author{
(TENSILE BEHAVIOUR OF GLASS FIBRE REINFORCED CEMENTS)
}

\author{
M. Laura Sánchez Paradela, Departamento de Construcción y Tecnologia Arquitectónicas \\ E.T.S. de Arquitectura. Ciudad Universitaria. 28040 Madrid.
}

Vicente Sánchez Gálvez, Departamento de Ciencias de Materiales

E.T.S. de Ingenieros de Caminos. Ciudad Universitaria.

28040 Madrid.

ESPAÑA

Fecha de recepcion: 5-IV-91

\section{RESUMEN}

El cemento reforzado con fibras de vidrio (GRC) es un material compuesto que se viene utilizando ampliamente en el campo de la Construcción. Présenta múltiples aplicaciones debido a sus buenas propiedades resistentes y de protección frente al fuego y la corrosión. Sin embargo, sufre un deterioro con el tiempo, que afecta a sus propiedades mecánicas, principalmente a su ductilidad, volviéndose frágll y agrietándose bajo pequeñas deformaciones.

Por tal motivo y con el fin de predecir el comportamiento mecánico del material a corto y a largo plazo, se ha desarrollado un extenso programa experimental, empleando tanto material joven como envelecido. Se han realizado numerosos ensayos de tracción directa, utilizando probetas de GRC con diversos tipos de fibras y empleando distintos métodos de fabricación para una comparación de resultados. Es la primera vez que se realizan ensayos de tracción directa en España sobre probetas de GRC.

\section{SUMMARY}

Glassfibre Reinforced Cement (GRC) is a composite material widely used in the field of bullding construction. It offers multiple applications due to its high strength as well as fire and corrosion resistance. However, it degradates with time, affecting its mechanical properties, mainly its ductility, becoming progressively brittle and cracking under low deformations.

Therefore, with the aim of predicting the mechanical behaviour of the material, both at short time and long time, a wide experimental program has been carried out, testing fresh material as well as aged material. A high number of tensile tests have been performed, using GRC specimens with different kind of fibres and different manufacturing processes for comparison of results. It must be pointed out that it is the first time that tensile tests of GRC specimens have been carried out in Spain.

\section{INTRODUCCION}

Un método ampliamente extendido para mejorar la resistencia a tracción de los cementos y morteros consiste en la adición de fibras de refuerzo, dando origen a los fibrocementos en los que se utilizó al principio únicamente la fibra de asbesto o amianto. Posteriormente y debido a la prohibición de su uso en diversos países por razones de salud, se han investigado nuevas fibras para el refuerzo de los cementos, tales como las de acero, vidrio, nylón, polipropileno, sisal, carbono, aramida, etc. Sin embargo, por razones fundamentalmente económicas, muy pocas de estas fibras han llegado a industrializarse y emplearse extensamente en el campo de la Construcción. Entre estas últimas se encuentra la fibra de vidrio que, utilizada para el refuerzo de los cementos, da origen al denominado GRC ("Glassfibre Reinforced Cement") que viene empleándose desde hace unos 30 años en la Construcción (1).

En el GRC se utiliza por lo general un cemento ordinario tipo Portland, mientras que para el refuerzo se emplea la fibra de vidrio constituida por un número elevado de filamentos para formar hilos que se cortan en longitudes pequeñas.

En cuanto a los tipos de fibra de vidrio utilizadas, inicialmente fue la fibra de vidrio $E$, empleada normal- 
mente en la fabricación de plásticos reforzados. Posteriormente, tras comprobarse que esta fibra sufría un ataque químico en presencia de los álcalis, comenzó a utilizarse la fibra de vidrio AR ("alkali resistant"), desarrollada por la Compañía inglesa Pilkington Brothers y comercializada con el nombre de Cem-FlL. En la tabla 1 pueden observarse las propiedades de ambas fibras (2).

Tabla 1. Composiciones químicas y propiedades mecánicas de fibras de vidrio utilizadas en el refuerzo de cementos.

\begin{tabular}{|lcccccccc|}
\hline & $\mathrm{SiO}_{2}$ & $\mathrm{Na}_{2} \mathrm{O}$ & $\mathrm{B}_{2} \mathrm{O}_{3}$ & $\mathrm{Al}_{2} \mathrm{O}_{3}$ & $\mathrm{MgO}$ & $\mathrm{CaO}$ & $\mathrm{ZrO}_{2}$ & $\mathrm{Li}_{2} \mathrm{O}$ \\
\hline Fibra E & 52,4 & 0,8 & 10,4 & 14,4 & 5,2 & 16,6 & - & - \\
Fibra A & 72,2 & 13 & - & 1,8 & 3,5 & 9,5 & - & - \\
Fibra AR & 71 & 11 & - & 1 & - & - & 16 & 1 \\
\hline \multicolumn{7}{c}{ Tensión de Rotura } & Modulo de Young & Alargam. \\
& Mpa. & & Gpa. & en Rotura $\%$ \\
\hline Fibra E & 3500 & & 72,5 & & 4,8 \\
Fibra A & 3100 & & 65 & & 4,7 \\
Fibra AR & 2500 & & 70 & & 3,6 \\
\hline
\end{tabular}

Entre los sistemas utilizados en la fabricación de paneles reforzados con fibras de vidrio, se utilizan diversos procedimientos, siendo los dos siguientes lo más usuales:

Premezclado o "pre-mix", donde se amasan conjuntamente la fibra de vidrio, en forma de hilos cortados y el cemento antes de verterlos en el molde. Los fabricantes de fibra desaconsejan este método debido al posible daño de la fibra durante el amasado. Otros aconsejan utilizar una amasadora con aspas de material plástico para paliar el efecto nocivo del amasado.

Proyección o "spray-up", donde se amasa previamente el cemento con el agua y, en su caso, los áridos, bombeándose la pasta que una máquina proyecta sobre el molde simultáneamente con los hilos cortados automáticamente de la bobina. En muchos casos a este proceso se le añade uno de succión del agua ("spraysuction") para reducir la plasticidad y conseguir un material más seco y consistente. Las láminas producidas tras la succión del agua, pueden remoldearse para fabricar paneles corrugados, tuberías, etc $(3,4)$. Gracias a su versatilidad, uniformidad del producto y la venta. ja de la orientación en 2 dimensiones y al azar de las fibras, este método se considera el más idóneo para la fabricación de paneles de GRC.

Las realizaciones prácticas de este material en el campo de la Construcción son numerosísimas. EI GRC se viene utilizando principalmente en la producción de piezas prefabricadas en fachadas mediante paneles "sandwich" de GRC, con un núcleo central de poliestireno expandido. Asimismo se ha extendido su empleo en decoración de interiores y como recubrimiento de fachadas en edificios ya construidos con anterioridad y que han sufrido un deterioro con el tiempo. A otros niveles, su uso se ha extendido incluso a la fabricación de "fingers" o brazos de acceso a los aviones (5).

Los paneles de GRC presentan buenas propiedades resistentes, baja densidad y alta resistencia a la corrosión y al fuego, por lo que resultan adecuados para el cierre de fachadas y se espera un desarrollo futuro llegándose a la producción en masa (6).

Sin embargo, es un hecho conocido desde hace más de 15 años, que los GRC sufren un deterioro con el tiempo que afecta a sus propiedades mecánicas y muy especialmente a su ductilidad, volviéndose frágiles y agrietándose bajo pequeñas deformaciones. Con el fin de predecir el comportamiento mecánico del material a corto y a largo plazo, es necesario conocer "a priori" las propiedades mecánicas a tracción de este material tanto joven como envejecido.

En el programa experimental desarrollado, se han realizado diversos ensayos de tracción directa utilizando probetas de GRC con distintos tipos de fibras y empleando métodos diferentes de fabricación tanto sobre material joven como envejecido. Destacaremos que es la primera vez que se realizan ensayos de tracción en España con cementos reforzados con fibras de vidrio.

\section{DESCRIPCIÓN DEL PROGRAMA DE ENSAYOS}

El programa experimental consistió en la realización de ensayos de flexión y tracción simple, aunque en este artículo nos atendremos a estos últimos, por ser de mayor interés y presentar más ventajas. Se emplearon probetas de GRC fabricadas con cemento Portland ordinario como matriz y fibras de vidrio de caracteristicas diferentes como refuerzo. En todos los casos, las dimensiones de las probetas fueron las mismas así como la fracción volumétrica empleada, para una más precisa comparación de resultados.

El programa de ensayos se dividió en 2 series por motivos de adaptación a los medios disponibles principalmente, $y$, asimismo, por un intento de mejorar las condiciones de fabricación de los materiales y, consecuentemente, las de los ensayos posteriores.

\subsection{Fabricación de probetas de la primera serie}

En la primera serie, se fabricaron probetas de dimensiones $250 \times 50 \times 10 \mathrm{~mm}$ aproximadamente, a partir de 
placas de $0,75 \times 1,00 \mathrm{~m}$ y $10 \mathrm{~mm}$ de espesor, con lo que se obtuvieron 60 probetas por placa. Las placas se fabricaron en un molde de madera contrachapada de haya, de dimensiones $150 \times 100 \times 5 \mathrm{~cm}$ cuyos laterales se hicieron abatibles mediante bisagras con el fin de facilitar el desmoldado posterior de las placas. Por igual motivo, se colocó un listón central de $1 \mathrm{~cm}$ de altura, que divide al molde en dos partes iguales, obteniéndose de este modo 2 placas idénticas por cada molde.

En esta primera serie, se fabricaron dos placas de cemento Portland exclusivamente (sin adición de fibras), para comparación de resultados (placa l), y una segunda pareja de placas empleando como matriz el mismo cemento $y$, como refuerzo, fibras de vidrio $E$ tratadas con polímero termoplástico "Forton" de $12 \mathrm{~mm}$ de longitud, disposición bidimensional y al azar, que fue suministrada por "Vetrotex" (placa II). La fracción volumétrica fue del $5 \%$.

Se eligió un valor de la relación agua/cemento del material de 0,35 como la más idónea para lograr una consistencia seca que aportara una mayor resistencia a cada placa. En la tabla 2 se indica la numeración de las placas y la proporción de las mezclas utilizadas.

Tabla 2. Materiales y proporciones de las mezclas

\begin{tabular}{|c|c|c|c|c|}
\hline \multirow{2}{*}{ Placas } & \multicolumn{4}{|c|}{ Materiales y proporciones } \\
\cline { 2 - 5 } & $\begin{array}{c}\text { Cemento } \\
\mathrm{kg}\end{array}$ & $\begin{array}{c}\text { Agua } \\
\mathrm{kg}\end{array}$ & $\begin{array}{c}\text { Fibra E } \\
\mathrm{kg}\end{array}$ & $\begin{array}{c}\text { Relación } \\
\text { agualcemento }\end{array}$ \\
\hline $\mathrm{I}$ & $\begin{array}{c}\text { Portland 35- II-A } \\
13,3\end{array}$ & 4,65 & - & 0,35 \\
$\mathrm{II}$ & $\begin{array}{c}\text { Portland 35- II-A } \\
12,66\end{array}$ & 4,42 & $\begin{array}{c}\text { "Forton" } \\
0,9\end{array}$ & 0,35 \\
\hline
\end{tabular}

Para la fabricación de las placas de esta primera serie, se utilizó la técnica del premezclado empleando tiempos de amasada superiores a 2 minutos, de acuerdo con las recomendaciones de las Normas existentes. La pasta fresca se vertió en el molde, extendiéndose con ayuda de una espátula. A continuación se vibró utilizando la técnica de vibración del molde, mediante una vibradora manual de aguja. Las mezclas, una vez vibradas, se dejaron fraguar en el laboratorio a una temperatura ambiente de $20^{\circ} \mathrm{C}$ aproximadamente. Durante todo el tiempo de fraguado, se mantuvo el molde cubierto con una tela húmeda, con el fin de evitar posibles fisuras de las placas.

A las 48 horas se procedió al desmoldado de las placas (figura 1) trasladándolas a continuación a una cámara de humedad a $20^{\circ} \mathrm{C}$ y un $95 \%$ de humedad relativa, para un curado de 28 días (figura 2). A los 20 días de curado, se extrajeron de la cámara de humedad para cortar las placas en probetas de $250 \times 50 \times 10 \mathrm{~mm}$,

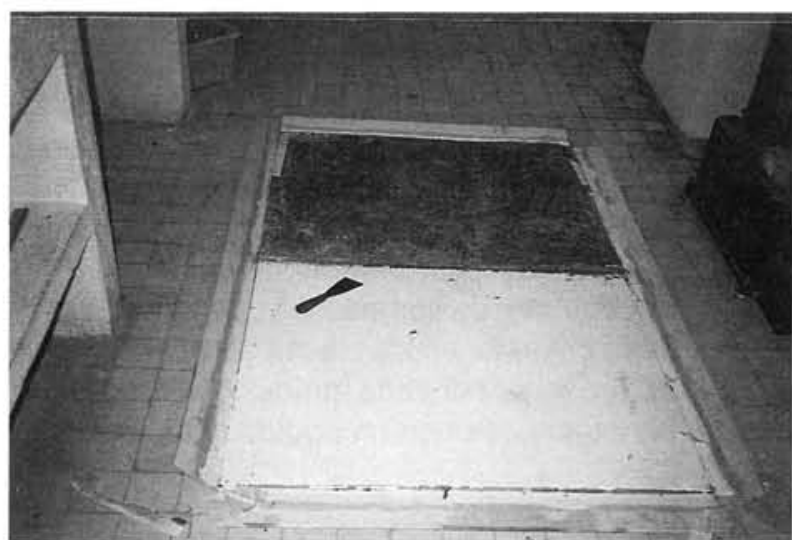

Fig. 1. Desmoldado de una de las placas.

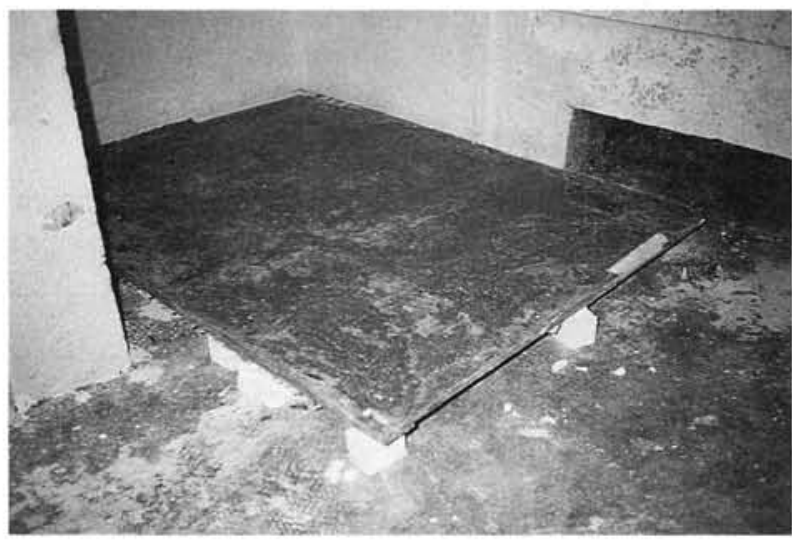

Fig. 2. Curado en cámara de humedad de las placas I y II.

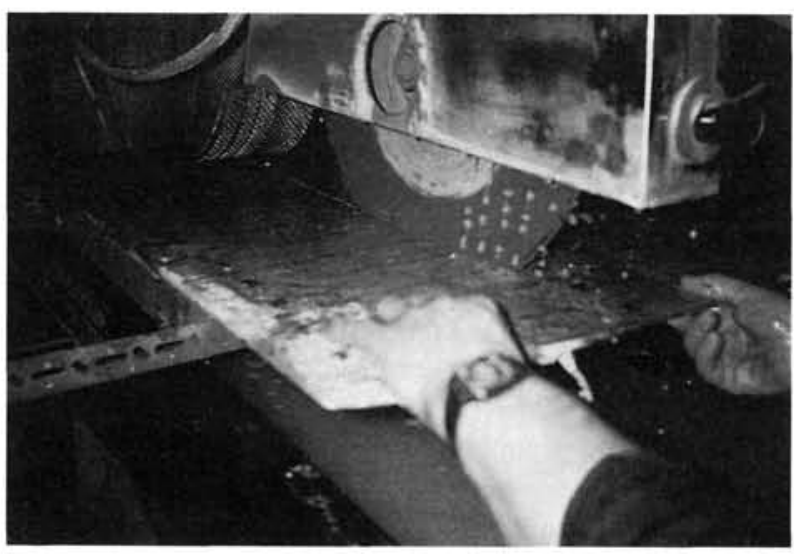

Fig. 3. Corte de las placas mediante cortadora radial.

mediante una cortadora radial provista de un sistema de refrigeración por agua para evitar la formación de polvo durante el proceso de cortado (figura 3). A continuación se numeraron las probetas y se devolvieron a la cámara de humedad para completar el período de curado, tras el cual comenzó el programa de ensayos.

http://informesdelaconstruccion.revistas.csic.es 


\subsection{Fabricación de probetas de la segunda serie}

Las dimensiones de las probetas de esta segunda serie fueron igualmente de $250 \times 50 \times 10 \mathrm{~mm}$, obtenidas a partir de placas de dimensiones $125 \times 80 \mathrm{~cm}$ y $10 \mathrm{~mm}$ de espesor. Para la fabricación de los dos tipos de probetas distintas, se utilizaron otros tantos moldes metálicos, con listones de separación que facilitasen el desencofrado posterior de las placas, resultando de es. te modo 80 probetas por cada molde. Previamente, se prepararon los moldes con un líquido desencofrante.

Se fabricaron dos mezclas distintas, utilizando un cemento Portland ordinario de mayor resistencia que el empleado en la preparación de las placas de la prime. ra serie. Los materiales y proporciones de las mezclas utilizadas en la preparación de estas dos placas (denominadas III y IV) se detallan en la tabla 3 , en la que se incluyen asimismo los valores correspondientes pa. ra las placas I y II (datos de moldes completos).

Tabla 3. Materiales y proporciones de las mezclas empleadas en la fabricación de las placas

\begin{tabular}{|c|c|c|c|c|}
\hline \multirow[b]{2}{*}{ Placas } & \multicolumn{4}{|c|}{ Materiales y proporciones } \\
\hline & $\underset{\mathrm{kg}}{\text { Cemento }}$ & $\underset{\mathrm{kg}}{\text { Agua }}$ & $\underset{\mathrm{kg}}{\text { Agua }}$ & $\begin{array}{c}\text { Fibra } \\
\mathrm{kg}\end{array}$ \\
\hline 1 & $\begin{array}{c}\text { Portland } 35-11-A \\
26,6\end{array}$ & - & 9,3 & - \\
\hline II & $\begin{array}{l}\text { Portland } 35-11-A \\
25,33\end{array}$ & - & 8,85 & $\begin{array}{c}\text { E "Forton" } \\
1,8\end{array}$ \\
\hline III & $\begin{array}{c}\text { Portland } 450-A R I \\
15,4\end{array}$ & 15,4 & 5,50 & $\begin{array}{c}\text { AR Cem-FIL-2 } \\
1,91\end{array}$ \\
\hline IV & $\begin{array}{c}\text { Portland } 450-A R I \\
15,4\end{array}$ & - & 5,38 & $\begin{array}{c}\text { AR Cem-FIL-2 } \\
1,09\end{array}$ \\
\hline
\end{tabular}

Las relaciones agua/cemento fueron de 0,35 en todos los casos excepto para la placa III, en la que se tomó el valor de 0,36 con el fin de obtener una mezcla más consistente debido a su contenido en arena. Se utilizó arena de sílice de 0,2 $\mathrm{mm}$ de grosor, de acuerdo con las recomendaciones de la Norma de GRC actualmente en preparación. Asimismo se añadió un superplastificante durante el amasado del cemento, agua y arena, con el fin de mejorar la trabajabilidad de la mezcla.

La fibra de vidrio empleada en las mezclas III y IV fue la AR del tipo comercial "Cem-FIL 2", de $35 \mathrm{~mm}$ de longitud y una fracción volumétrica del $5 \%$.

La pasta de cemento en los dos casos, se dosificó y amasó mecánicamente en un agitador de masa vertical. Finalizado el amasado, se trasladó a la máquina

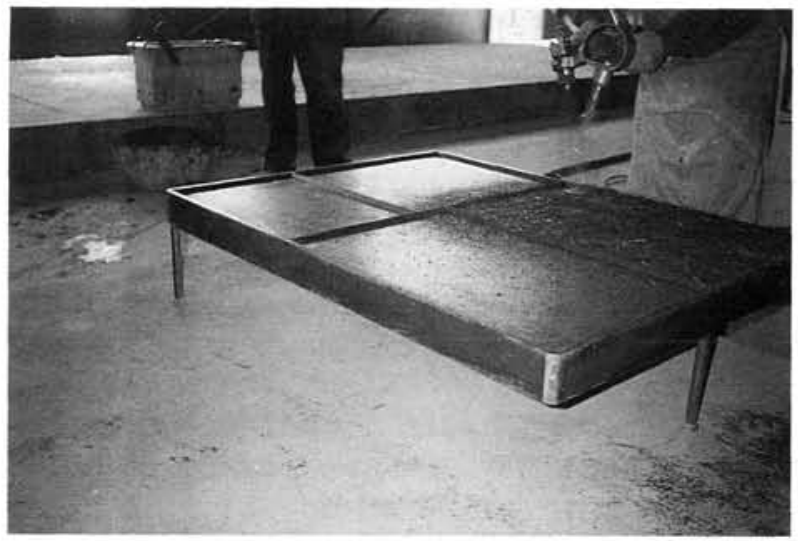

Fig. 4. Proyección simultánea de la pasta de cemento y la fibra de vidrio sobre el molde.

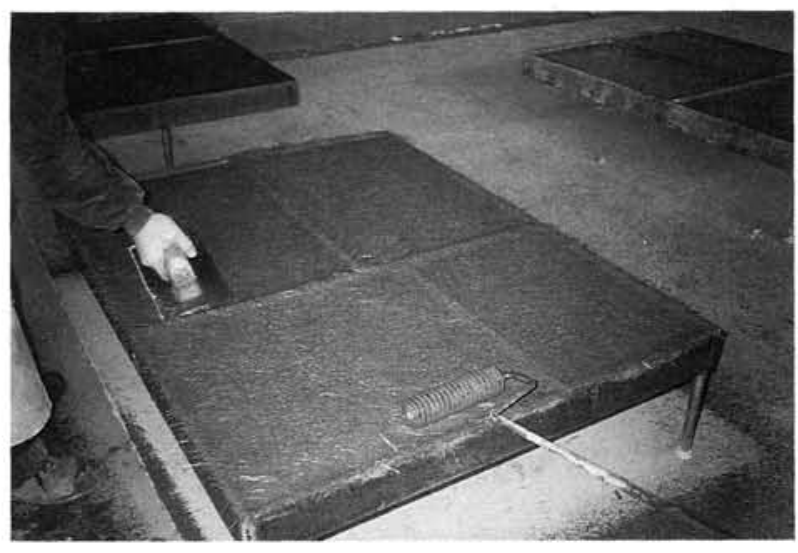

Fig. 5. Enrasado final con llana y rodillo.

de proyección ("spray-up"), previo tamizado de la mezcla en un tamiz de $4 \mathrm{~mm}$ con el objeto de eliminar posibles partículas gruesas en la misma.

En la fabricación de las placas de esta segunda serie (placas III y IV), se utilizó una máquina de proyección o "spray-up", que proyectó sobre el molde la masa de cemento junto con la fibra, que, en forma de bobina o "rowing", fue cortada automáticamente por la misma máquina en hilos de $35 \mathrm{~mm}$ de longitud (figura 4).

Una vez conseguido el espesor necesario de $10 \mathrm{~mm}$, se compactó la mezcla mediante un rodillo metálico y se terminó la operación empleando la llana para uniformarla (figura 5).

Los dos moldes así preparados con las dos mezclas distintas, se mantuvieron curándose por espacio de 24 horas hasta completar el fraguado. A continuación se desmoldaron y las piezas se trasladaron a una cámara de humedad, donde se mantuvieron en un ambiente de $20^{\circ} \mathrm{C}$ y $95 \%$ de humedad relativa durante 27 dias (figura 6). Transcurrido este período, se recogieron las 


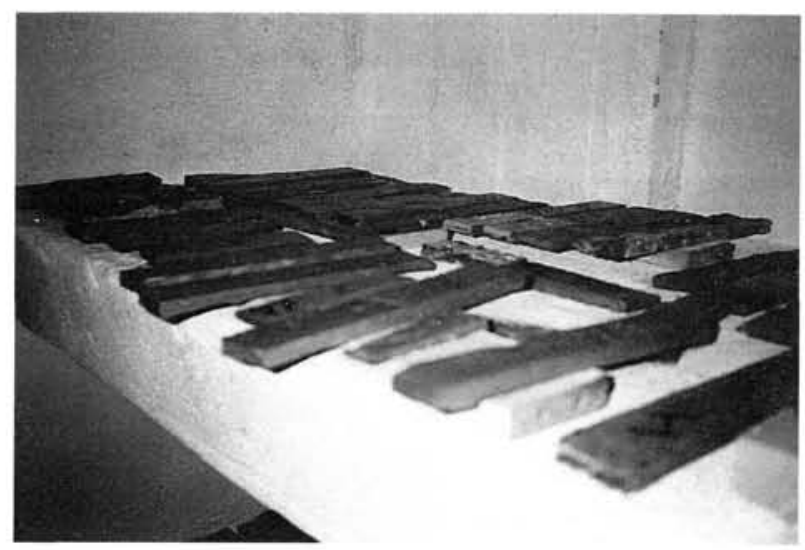

Fig. 6. Curado de las placas III y IV en la cámara de humedad.

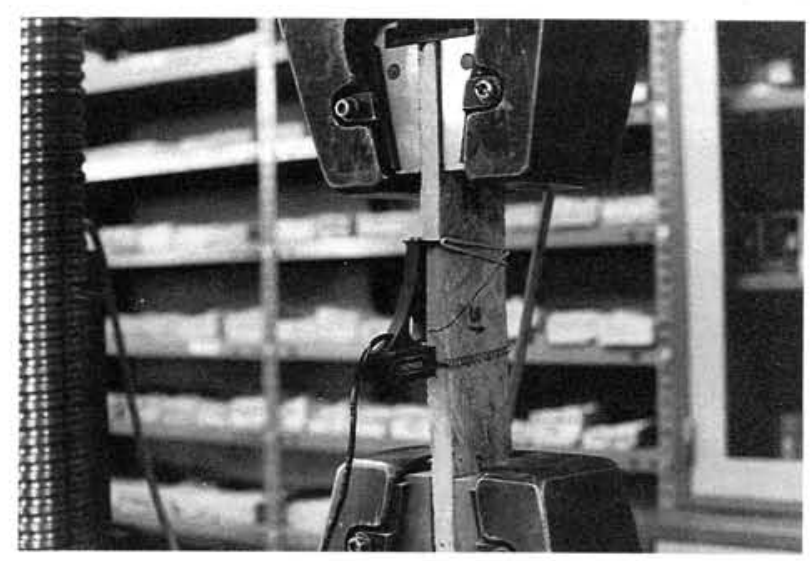

Fig. 7. Extensómetro utilizado en los ensayos de tracción.

placas y se trasladaron al laboratorio de ensayos donde se cortaron con la misma cortadora radial de las placas I y II, dejándolas secar al aire durante 24 horas tras el proceso de cortado. A partir de ese instante dio comienzo el programa de ensayos.

\subsection{Ensayos mecánicos de tracción simple}

Transcurrido el período de curado, se tomaron 6 probetas de cada mezcla para realizar ensayos de tracción simple y el resto se destinó a envejecimiento acelerado, sumergiéndolas en agua a $50^{\circ} \mathrm{C}$ para ensayarlas posteriormente a tracción a distintos intervalos de tiempo.

Los ensayos de tracción simple se llevaron a cabo en una máquina universal de ensayos mecánicos servohidráulica "SUZPECAR" de fabricación nacional de 10 t de capacidad. Las cargas se miden con una célula en serie con la probeta, de 10 t de capacidad y una precisión de $1 \mathrm{~kg}$. El sistema se completa con un amplificador y registrador de doble pluma y servo.
Para los ensayos de tracción simple, se eligió una velocidad de desplazamiento del carro de $0,5 \mathrm{~mm} / \mathrm{min}$.

Se escogieron 6 probetas de características similares, que se sujetaron a la máquina por medio de mordazas mecánicas que, a su vez, estaban sujetas mediante mordazas hidráulicas de la máquina. La distancia libre entre mordazas fue de $15 \mathrm{~cm}$ aproximadamente. En esa zona libre, se fijó a la probeta un extensómetro "INSTRON", de $5 \mathrm{~cm}$ de base de medida y un $10 \%$ de alargamiento máximo con una precisión en la medida de deformaciones de 10-5 (figura 7). El extensómetro se fijó directamente a la probeta sujetando las cuchillas mediante dos bandas de caucho.

Es preciso destacar que es la primera vez que se realizan en España ensayos de tracción directa de probetas de cemento reforzado con fibras de vidrio, con medida de deformaciones mediante extensómetro sujeto a la probeta.

Las lecturas de la carga y de la deformación proporcionados por la célula de carga y el extensómetro, respectivamente, se recogieron de forma automática en un Sistema de Adquisición de Datos tipo "HEWLETT PACKARD 3495", tomándose un par de lecturas cada décima de segundo.

Las lecturas se almacenaron en una cassette y un ordenador "HEWLETT PACKARD 9825" elaboró los resultados, calculando tensiones a partir de la lectura de cargas, dividiendo por la sección recta de cada una de las probetas, previamente medida con un calibre de $0,1 \mathrm{~mm}$ de precisión. Finalmente, los resultados se presentan en forma de gráficas tensión-deformación, dibujadas por la impresora del ordenador.

\subsection{El envejecimiento acelerado}

El empleo del método del envejecimiento acelerado se basa en la medida de la pérdida de resistencia a altas temperaturas (alrededor de $50^{\circ} \mathrm{C}$ ) en tiempos cortos, como medio de predecir la pérdida de resistencia a temperaturas normales (alrededor de $20^{\circ} \mathrm{C}$ ) durante largos periodos de tiempo. Este concepto presupone, entre otros, el hecho de que la disminución de resistencia del material está directamente relacionada con la ve. locidad de alguna reacción química y que dicha reacción química constituye en esencia el mismo mecanismo que controla el envejecimiento en el intervalo de temperaturas de $20^{\circ} \mathrm{C}$ a $80^{\circ} \mathrm{C}$. La validez de estas hipótesis queda establecida, al menos de forma indirecta, cuando los datos de envejecimiento acelerado se correlacionan con datos obtenidos a partir de en. sayos de envejecimiento en ambientes naturales. 
En las tablas 4 y 5 , se presenta la correlación de equivalencias entre tiempos en envejecimiento acelerado y envejecimiento natural en distintos ambientes $(7,8$, 9,10 y 11).

Tabla 4. Equivalencia entre un día en agua a distintas temperaturas y tiempo de envejecimiento natural en Inglaterra para GRC con fibra de vidrio Cem.FIL-1.

\begin{tabular}{|c|c|c|}
\hline \multirow{2}{*}{$\begin{array}{c}\text { Temperaturas }\left({ }^{\circ} \mathrm{C}\right) \\
\text { un día en agua }\end{array}$} & \multicolumn{2}{|c|}{ Equivalencia en envejecimiento natural } \\
\cline { 2 - 3 } & dias & años \\
\hline 80 & 1672 & 4,6 \\
70 & 693 & 1,9 \\
60 & 272 & 0,75 \\
50 & 101 & 0,29 \\
\hline
\end{tabular}

Tabla 5. Equivalencia entre un día en agua a $50^{\circ} \mathrm{C}$ y tiempo de envejecimiento natural en distintos ambientes para GRC con fibra de vidrio Cem-FIL-1.

\begin{tabular}{|l|c|c|}
\hline \multicolumn{1}{|c|}{ Ciudad } & $\begin{array}{c}\text { Temperaturas medias } \\
\left({ }^{\circ} \mathrm{C}\right)\end{array}$ & $\begin{array}{c}\text { Envejecimiento natural } \\
\text { días }\end{array}$ \\
\hline Montreal & 7 & 160 \\
Nueva York & 12 & 82 \\
Tokio & 15 & 55 \\
Johanesburgo & 16 & 49 \\
Miami & 24 & 18 \\
\hline
\end{tabular}

\section{RESULTADOS EXPERIMENTALES}

\subsection{Resultados de la primera serie}

\section{* A los 28 dias}

\section{- Placa I}

La figura 8 presenta las curvas resultantes de los ensayos con algunas de las 6 probetas, donde puede apreciarse la escasa resistencia y ductilidad de las probetas fabricadas exclusivamente con cemento.

En la mayoria de las probetas, la rotura ha tenido lugar en la zona central de las mismas, confirmando la validez de los ensayos y apreciándose claramente la rotura a $45^{\circ}$ tipica de este material

\section{- Placa II}

En la figura 9 se muestran algunas curvas tensióndeformación de las 6 probetas ensayadas. Es notoria la mayor resistencia alcanzada por este material de

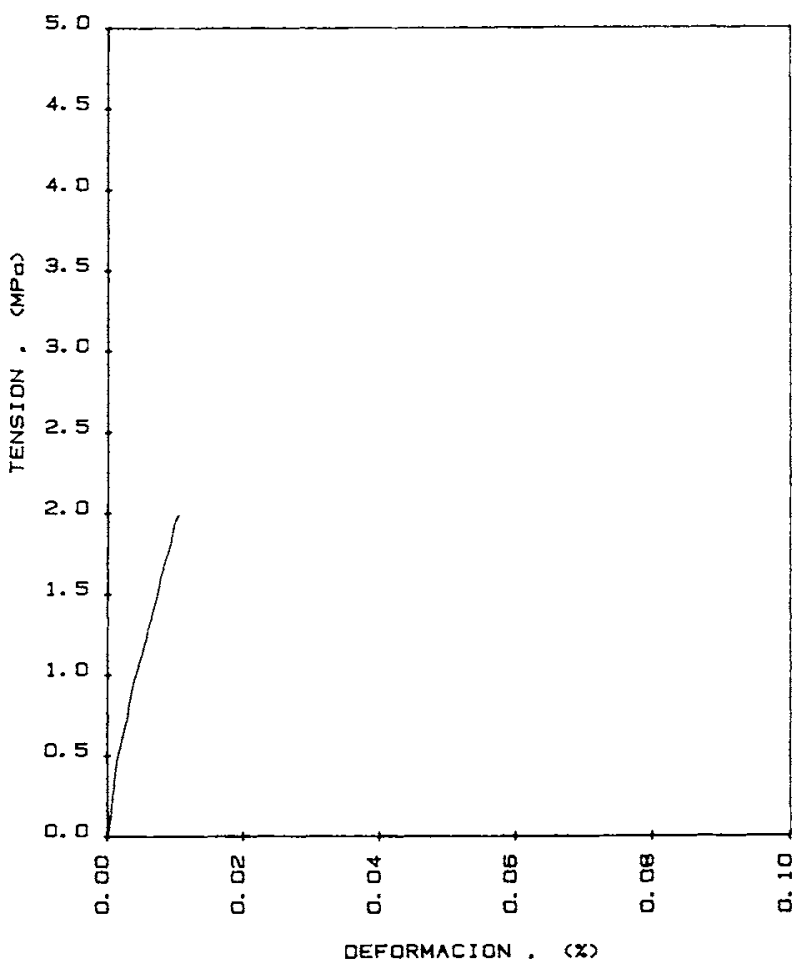

Fig. 8. Curvas tensión-deformación a tracción de algunas probetas de la placa l a los 28 dias.

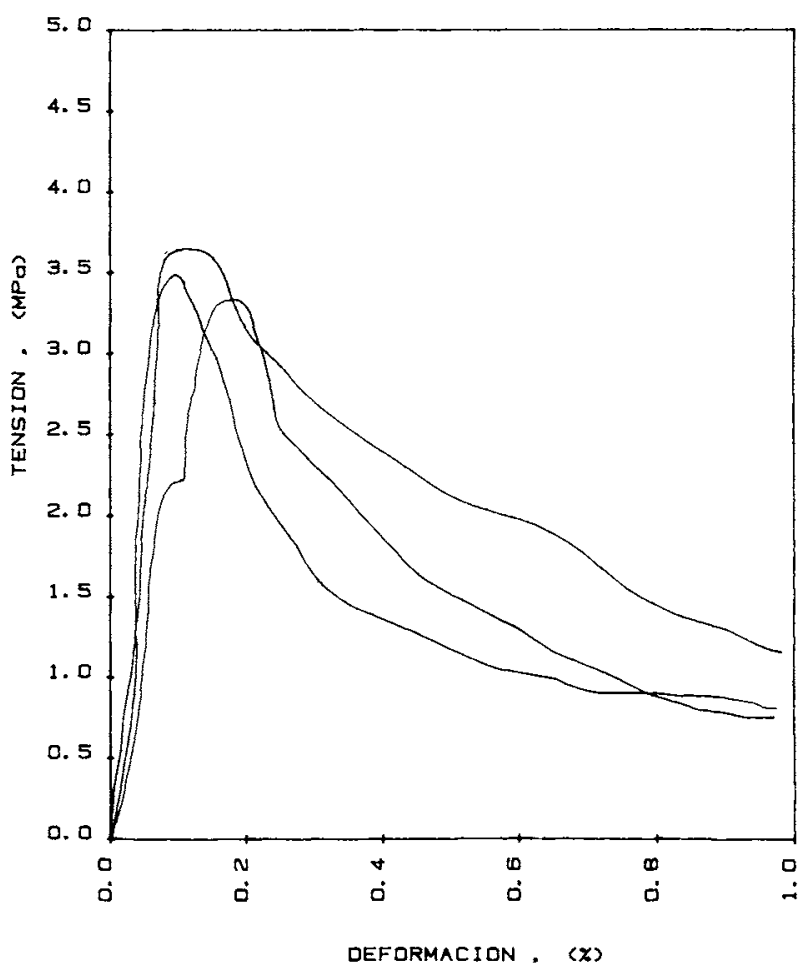

Fig. 9. Curvas tension-deformación a tracción de algunas probetas de la placa ll a los 28 días.

GRC en relación con la pasta de cemento, observándose sobre todo una mayor ductilidad, ya que con deformaciones incluso del 3\% no se ha logrado la sepa. ración completa de las probetas en dos mitades. No obstante, con esta placa Il, no se observan diferencias 


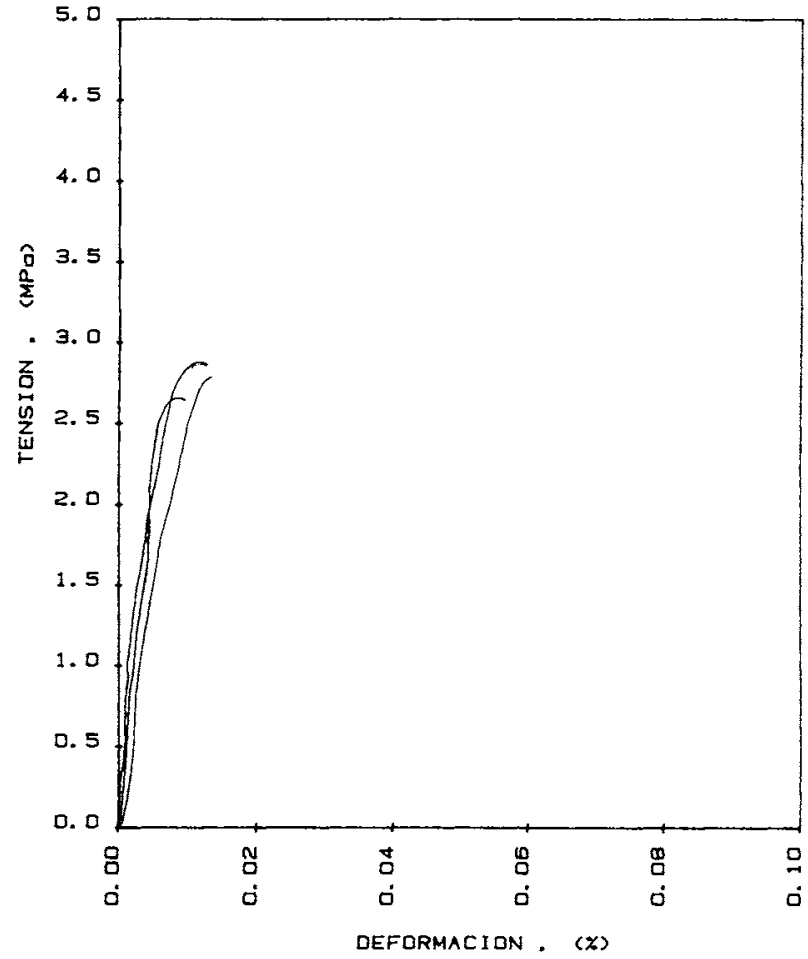

Fig. 10. Curvas tension-deformación a tracción de algunas probetas de la placa /l tras 1 semana de envejecimiento acelerado.

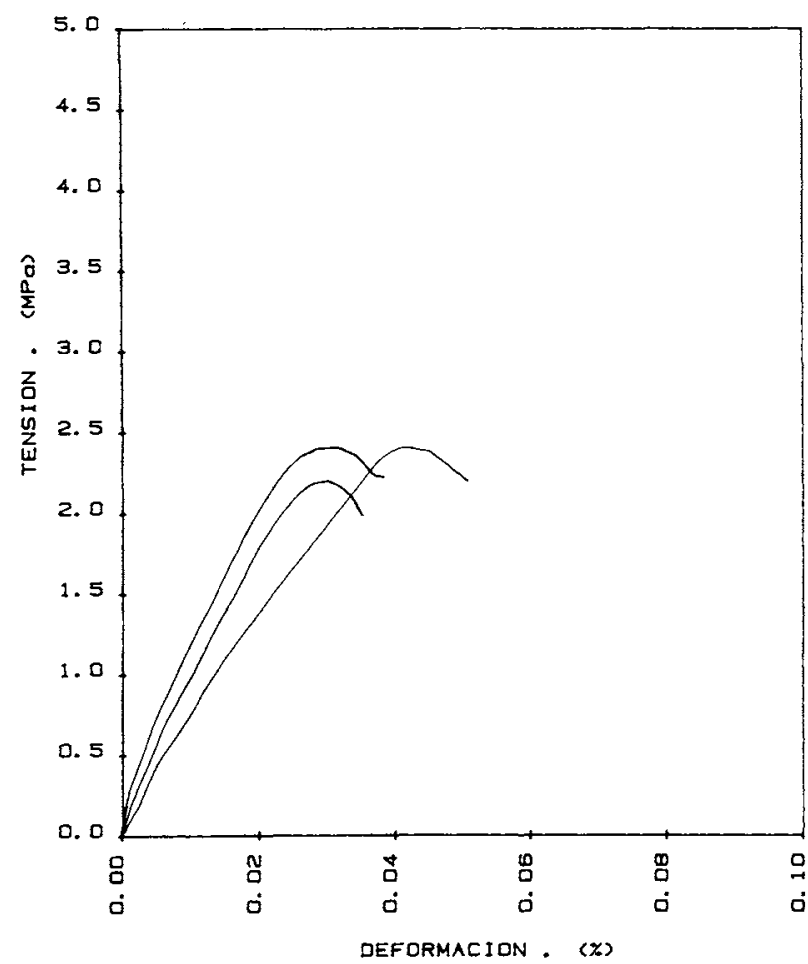

Fig. 11. Curvas tensión-deformación a tracción de algunas probetas de la placa II tras 4 semanas de envejecimiento acelerado.

notables entre la tensión de inicio de la fisuración (LOP) y la tensión de rotura (UTS) por lo que la deformación observada tras la carga máxima se debe a un proceso de arrancamiento sucesivo de fibras a tensiones decrecientes.
A diferencia de la placa I, la rotura es sensiblemente normal a la dirección de aplicación de la tensión. Tam. bién se comprueba que las fibras en la zona de la rotura han sufrido un proceso de arrancamiento (observable en las micrografías siguientes), congruente con la pequeña longitud de las mismas en esta serie, $12 \mathrm{~mm}$.

\section{* A 1 semana de envejecimiento acelerado}

Lógicamente, no se han efectuado ensayos de envejecimiento sobre la placa I, constituida por pasta de cemento exclusivamente.

\section{- Placa II}

Tras 1 semana de envejecimiento acelerado, se observan ya roturas a $45^{\circ}$, similares a las obtenidas en los ensayos de la placa I de pasta de cemento, y, en todo caso, no se observan las fibras en la región de la rotura, por lo que puede deducirse que no se ha producido el arrancamiento sucesivo de las fibras que se tenía en los ensayos a los 28 dias, por lo que la deformación de rotura se reduce drásticamente.

Este hecho se comprueba en la figura 10 donde se muestran algunos resultados obtenidos gráficamente con cada una de las 6 probetas ensayadas, apreciándose un ligero descenso de la resistencia y una fuerte reducción de la ductilidad, debido al proceso de envejecimiento acelerado a que fueron sometidas las probetas. El efecto más significativo es la desaparación, prácticamente total, de la deformación más allá de la carga máxima, por lo que la energía de fractura del material se reduce de forma considerable.

\section{* A 4 semanas de envejecimiento acelerado}

\section{- Placa II}

En la figura 11 pueden observarse los resultados de los ensayos de forma gráfica, que muestran de nuevo una ligera pérdida de resistencia y una fuerte reducción de la deformación de rotura. Estos resultados no difieren sustancialmente de los obtenidos tras 1 semana de envejecimiento acelerado, por lo que puede afirmarse que el GRC de esta placa II reforzado con fibra E "Forton", sufre una fragilización acusada en ensayos de envejecimiento acelerado que se completa prácticamente al cabo de 1 semana de inmersión en agua caliente a $50^{\circ} \mathrm{C}$. Este resultado es similar al obtenido por otros autores $(12,13)$. Las curvas tensión-deformación, prácticamente lineales hasta la rotura, no difieren apreciablemente de las obtenidas con pasta de cemento, por lo que puede afirmarse que las fibras E "Forton", tras un corto periodo de envejecimiento, son prácticamente ineficaces. 


\subsection{Resultados de la segunda serie}

\section{* A los 28 dias}

$$
\text { - Placa III }
$$

La figura 12 muestra los resultados de resistencia obtenidos. Las curvas tensión-deformación presentan en todos los casos un comportamiento inicial esencialmente elástico lineal y una rama a continuación en la que la tensión crece más lentamente hasta alcanzar la tensión de rotura, que corresponde a grandes deformaciones de la probeta. Una vez más, las roturas tienen lugar en la mayoría de los casos en la región central de la probeta, confirmando la validez de los ensayos.

\section{- Placa IV}

Tanto en los ensayos de tracción con esta placa, como en los realizados con probetas de la placa III, que recordamos sólo difieren en la adición de arena en esta última, pero que tienen la misma clase de refuerzo, fibras AR de $35 \mathrm{~mm}$ de longitud, se observa el mismo tipo de rotura, aproximadamente normal a la dirección de aplicación de la tensión y con una múltiple fisuración previa a alcanzarse la tensión de rotura durante el ensayo.

La figura 13 muestra algunas de las curvas tensióndeformación obtenidas durante los ensayos, que presentan un aspecto semejante a las de la placa III. Se observa, no obstante, que las resistencias alcanzadas por estas probetas son mayores, lo que indica que la adición de arena reduce los niveles de resistencia, no observándose sin embargo variaciones apreciables en la deformación de rotura de ambas placas. En cualquier caso, las tensiones de rotura, tanto en la placa III como en la placa IV son muy superiores (entre 2 y 3 veces) a las que se obtuvieron con probetas de la placa II. Este hecho debe atribuirse a la reducida longitud de fibra $(12 \mathrm{~mm}$ ) utilizada para el refuerzo del material de la placa II, en comparación con los $35 \mathrm{~mm}$ de longitud de fibra empleada en el refuerzo de los materiales de las placas III y IV.

\section{* A 1 semana de envejecimiento acelerado}

\section{- Placa III}

La observación de las probetas indica que la rotura sigue siendo normal al eje de aplicación de la tensión y se produce una fisuración múltiple que indica que el envejecimiento no ha reducido la ductilidad del ma-

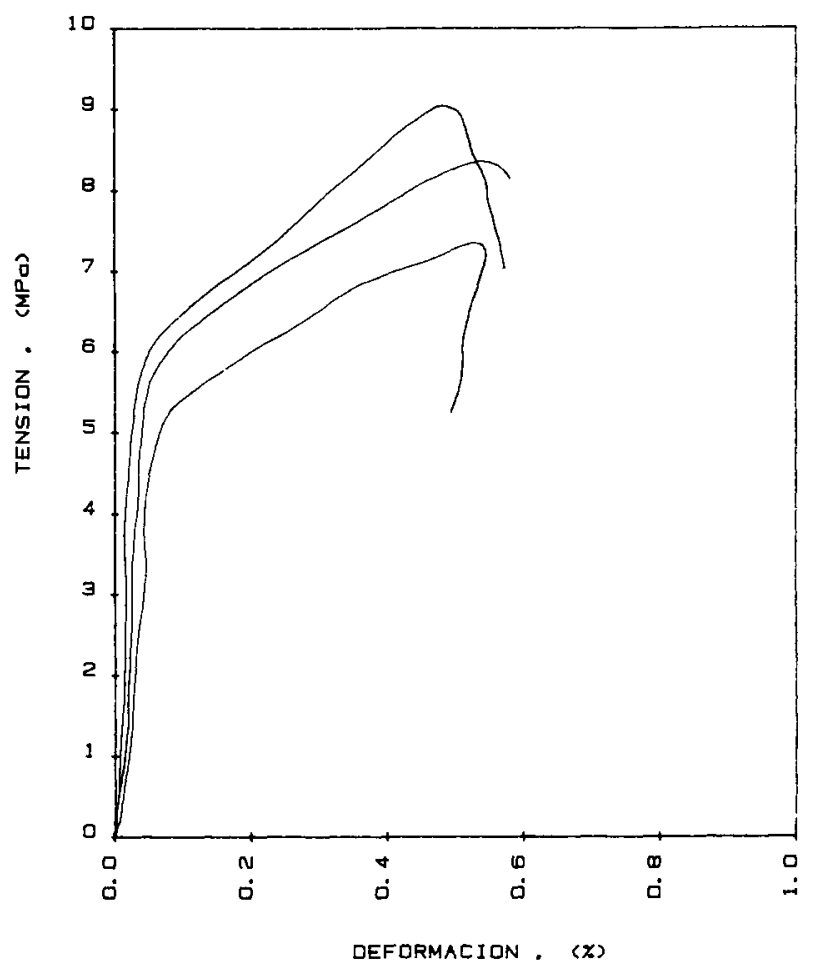

Fig. 12. Curvas tensión-deformación a tracción de algunas probetas de la placa III a los 28 dias.

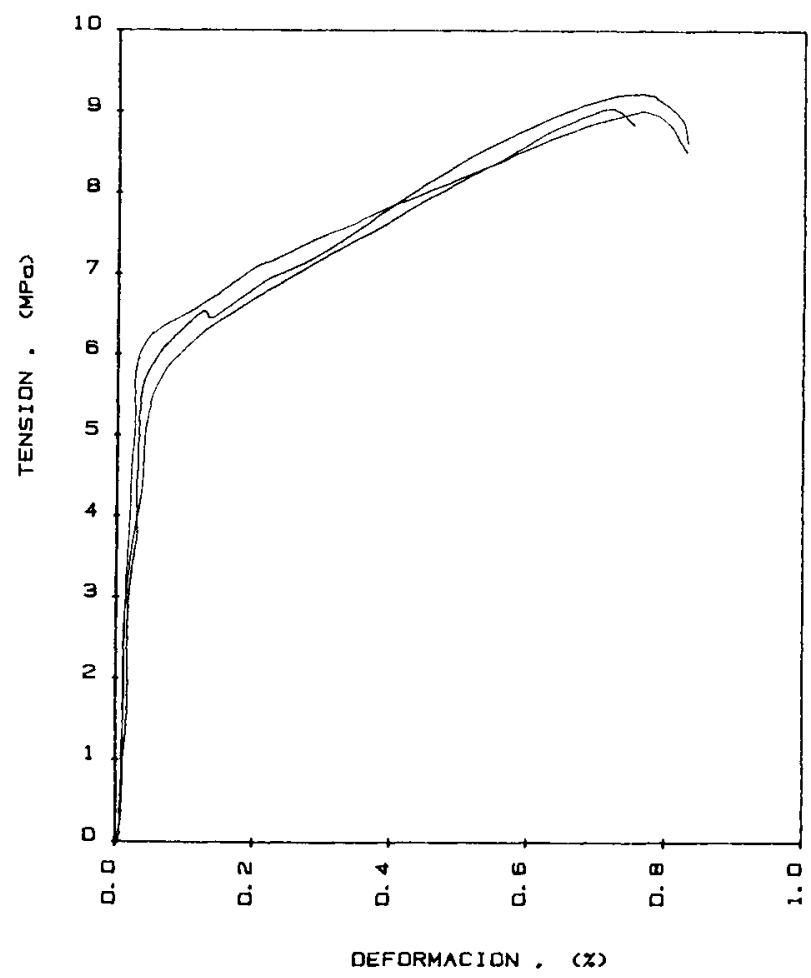

Fig. 13. Curvas tensión-deformación a tracción de algunas probetas de la placa IV a los 28 dias. 


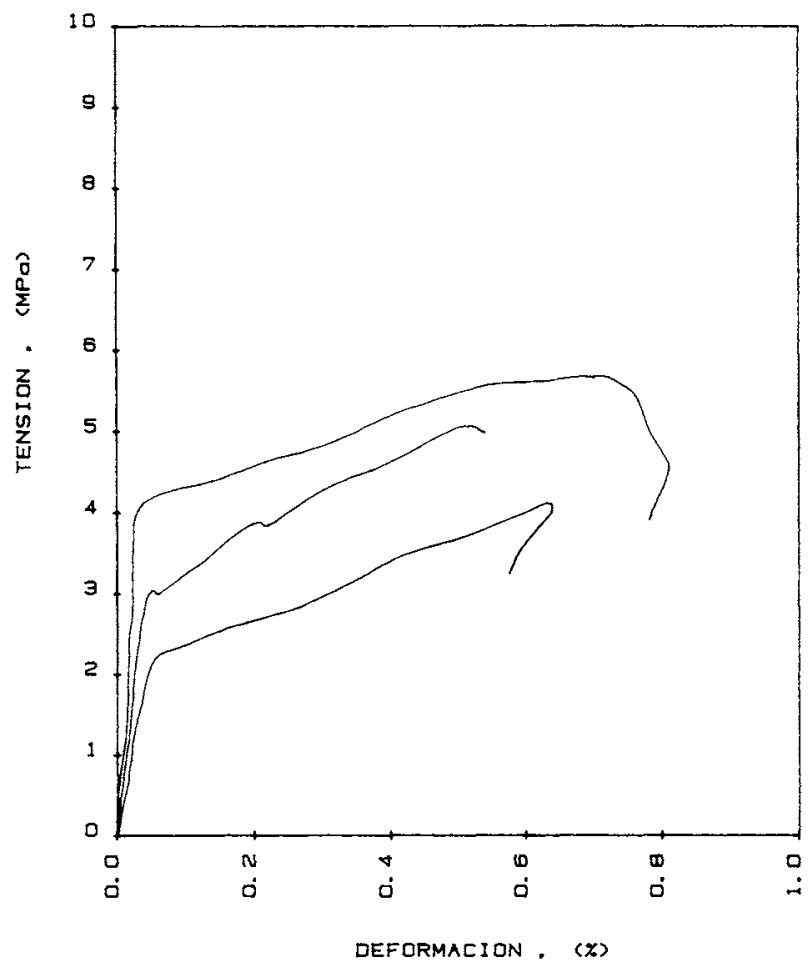

Fig. 14. Curvas tensión-deformación a tracción de algunas probetas de la placa III tras 1 semana de envejecimiento acelerado.

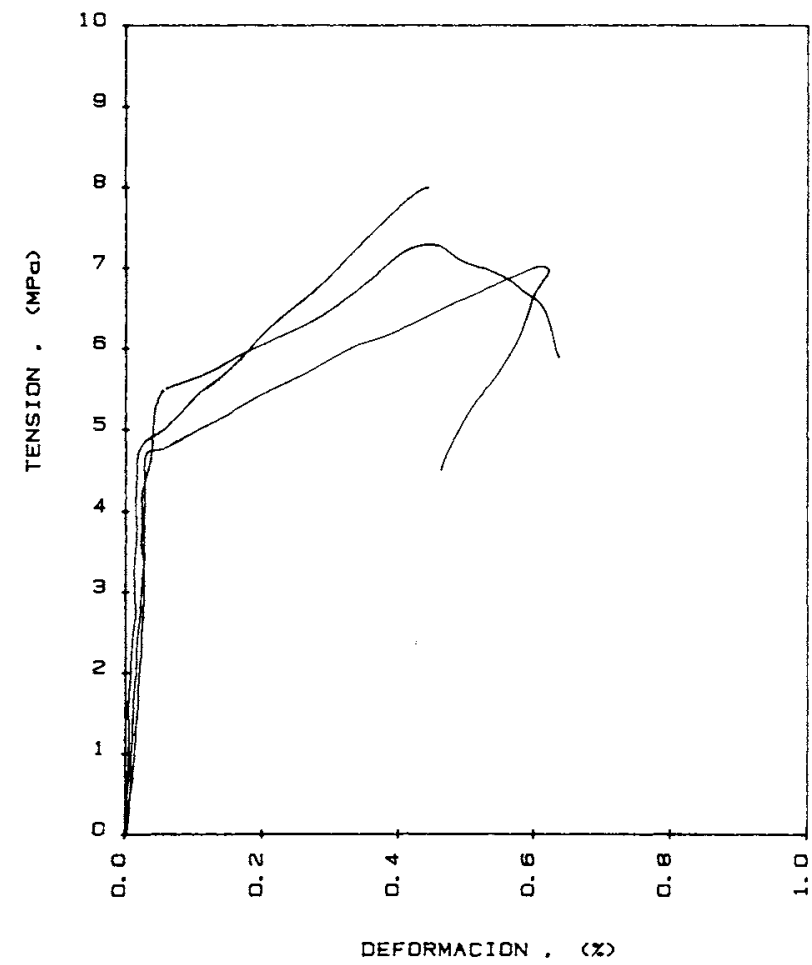

Fig. 15. Curvas tension-deformación a tracción de algunas probetas de la placa IV tras 1 semana de envejecimiento acelerado. terial de forma apreciable, a diferencia de los resultados obtenidos con la placa II.

La figura 14 muestra alguna de las curvas tensióndeformación de cada uno de los ensayos realizados. Se observa una pequeña reducción en la tensión de rotura respecto de los valores a 28 días, si bien el ma. terial conserva un comportamiento dúctil, con deformaciones de rotura prácticamente inalterables.

\section{- Placa IV}

En la figura 15 se presentan algunas curvas tensióndeformación de las probetas ensayadas. Todas las observaciones realizadas con los resultados de los ensayos de la placa III son igualmente válidas con la placa IV. Se comprueba también que al igual que sucedia en los ensayos a 28 días, la resistencia de las probetas de la placa IV es superior a las de la placa III, debido a la adición de arena.

\section{* A 4 semanas de envejecimiento acelerado \\ - Placa III}

La observación de las curvas tensión-deformación (figura 16) ofrece un aspecto totalmente distinto del que tenían las curvas a los 28 días o incluso tras 1 sema. na de envejecimiento acelerado. La tensión de rotura continúa disminuyendo, aunque es mucho más significativa la reducción de la ductilidad. Las deformaciones de rotura, que para probetas sin envejecer superaban el $0,5 \%$, ahora raramente alcanzan el $0,1 \%$. También se observa una mayor dispersión de resultados que la obtenida antes del proceso de envejecimiento. Podría atribuirse este hecho a un distinto grado de ataque de las probetas por una situación diferente dentro del baño de agua caliente.

\section{- Placa IV}

La figura 17 presenta los resultados obtenidos con algunas de las probetas ensayadas. En este caso, a diferencia de lo sucedido con la placa III, las probetas no muestran síntomas de envejecimiento. Es más, se encuentran valores de la tensión de rotura incluso superiores a los obtenidos tras 1 semana de envejecimiento acelerado, aunque ligeramente inferiores a los obtenidos con las probetas jóvenes. El límite de proporcionalidad sigue disminuyendo, pero la deformación media sigue creciendo tras la fisuración de la probeta alcanzándose valores correspondientes a la tensión de rotura similares a los obtenidos con las probetas jóvenes. 


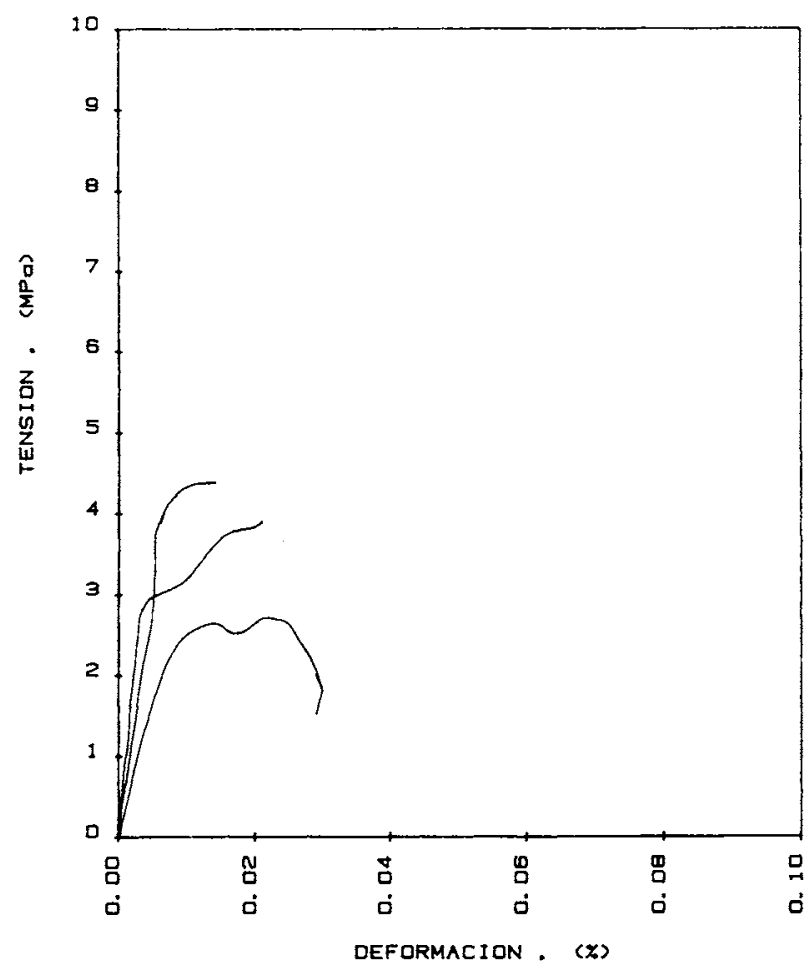

Fig. 16. Curvas tensión-deformación a tracción de algunas probetas de la placa III tras 4 semanas de envejecimiento acelerado.

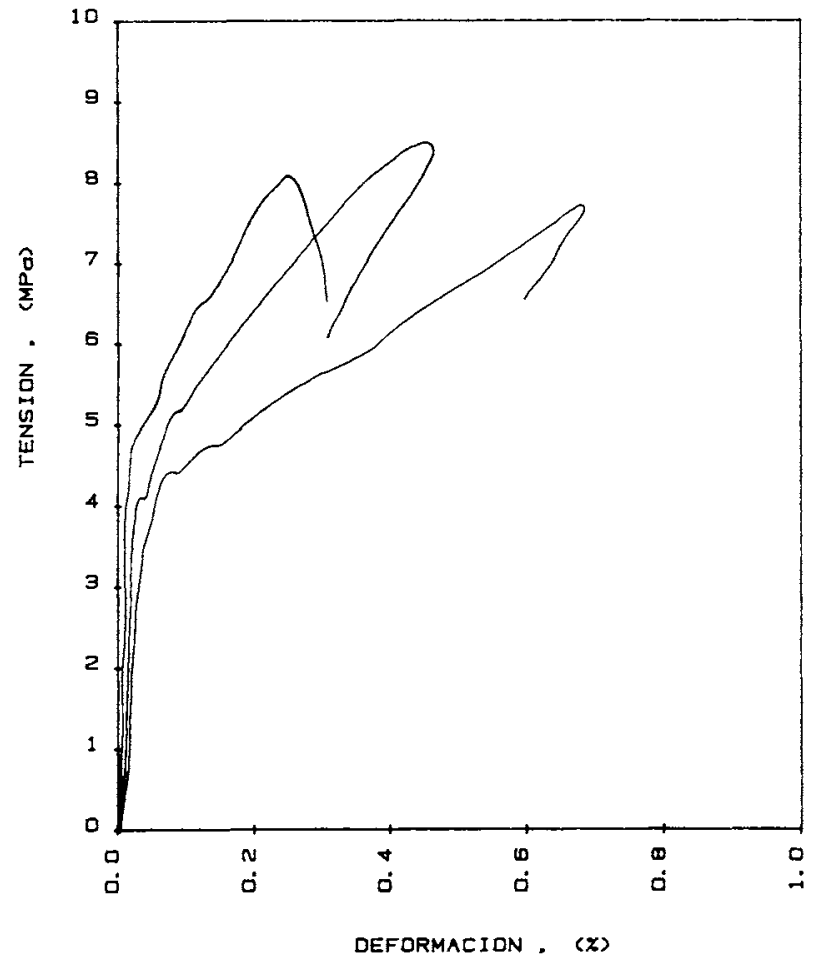

Fig. 17. Curvas tension-deformación a tracción de algunas probetas de la placa $I V$ tras 4 semanas de envejecimiento acelerado.
Puede concluirse, por tanto, que el GRC de la placa IV presenta una gran capacidad de deformación tras la fisuración, aún para probetas fuertemente envejecidas.

En la tabla 6 se presentan los resultados de los ensayos de tracción de las distintas placas en forma de valores medios.

Tabla 6. Resumen de resultados obtenidos en el ensayo de tracción simple.

\begin{tabular}{|c|c|c|c|c|}
\hline \multirow[b]{3}{*}{ A los 28 dias } & \multicolumn{4}{|c|}{ VALORES MEDIOS } \\
\hline & \multicolumn{2}{|c|}{ Primera serie } & \multicolumn{2}{|c|}{ Segunda serie } \\
\hline & Placa I & Placa II & Placa III & Placa IV \\
\hline $\operatorname{LOP}\left(\mathrm{kg} / \mathrm{cm}^{2}\right)$ & 18,53 & 31,00 & 43,50 & 47,33 \\
\hline UTS $\left(\mathrm{kg} / \mathrm{cm}^{2}\right)$ & 18,53 & 36,33 & 73,81 & 92,65 \\
\hline \multicolumn{5}{|l|}{$\begin{array}{l}\text { A } 1 \text { semana de } \\
\text { envel. acelerado }\end{array}$} \\
\hline $\operatorname{LOP}\left(\mathrm{kg} / \mathrm{cm}^{2}\right)$ & - & 23,50 & 35,17 & 47,67 \\
\hline UTS $\left(\mathrm{kg} / \mathrm{cm}^{2}\right)$ & - & 24,21 & 51,46 & 69,53 \\
\hline \multicolumn{5}{|l|}{$\begin{array}{l}\text { A } 4 \text { semanas de } \\
\text { envej. acelerado }\end{array}$} \\
\hline $\operatorname{LOP}\left(\mathrm{kg} / \mathrm{cm}^{2}\right)$ & - & 23,50 & 39,83 & 41,50 \\
\hline UTS $\left(\mathrm{kg} / \mathrm{cm}^{2}\right)$ & - & 23,50 & 48,39 & 84,48 \\
\hline
\end{tabular}

\subsection{Fractografia}

El programa experimental se ha complementado con observaciones al microscopio electrónico de barrido de las superficies de fractura de las probetas ensayadas a tracción, como comprobación adicional de los mecanismos de rotura de los distintos materiales ensayados. Es de destacar que estos estudios fractográficos se realizan por primera vez en España con GRC.

Previamente a la observación de las fracturas de las probetas al microscopio, se sometieron a un tratamien. to de metalización superficial con el fin de convertir la superficie en conductora para permitir su observación al microscopio.

A modo de ejemplo, se muestran algunas de las fractografias realizadas.

En la figura 18 se presenta la fractura de una probeta de la placa IV ensayada a los 28 dias. Se observa que las fibras están arrancadas de la superficie de fractura, lo que indica un tipo de rotura dúctil, propio de un GRC joven.

En la figura 19 se muestra una fractografia correspondiente a una probeta de la placa IV ensayada a trac- 


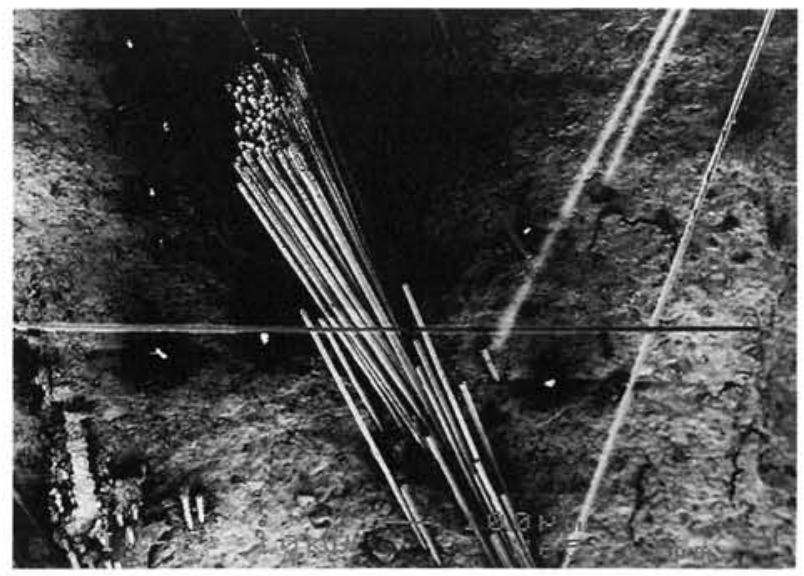

Fig. 18. Fractografía de una probeta de la placa IV ensayada a tracción a los 28 dias (magnificación: 100x).

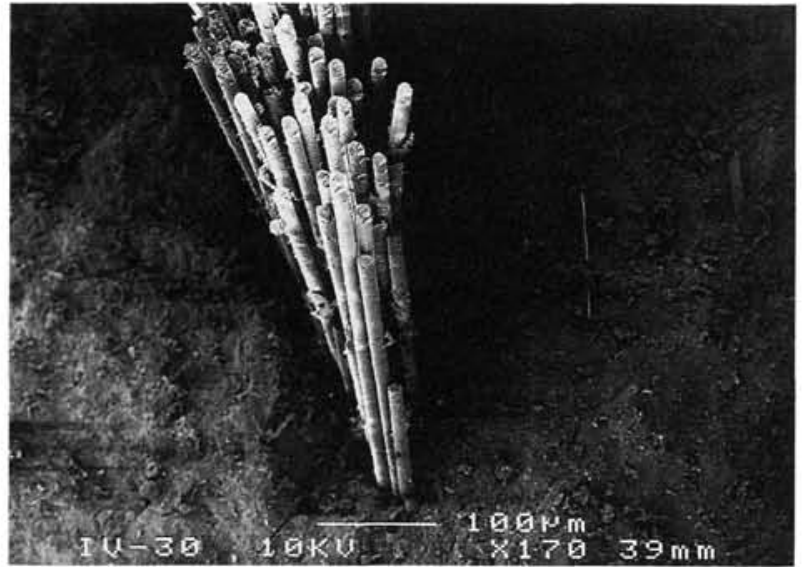

Fig. 19. Fractografía de una probeta de la placa IV ensayada tras 4 semanas de envejecimiento acelerado (magnificación. 260x).

ción simple tras 4 semanas de envejecimiento acelerado. En este caso, se observa que gran parte de los filamentos se han roto, aunque persiste el arrancamiento de las fibras, por lo que la rotura sigue siendo dúctil.

Contrariamente, en la figura 20 puede observarse la fractografía de una probeta de la placa II ensayada tras 4 semanas de envejecimiento acelerado. En contraste con las micrografías anteriores, se detecta claramente la rotura de todos los filamentos de la fibra casi a ras de la matriz, indicando una fragilidad del material. La fractografía que se muestra en la figura 21 corresponde a la misma probeta a mayor aumento, para observar con más detalle el deterioro de la película "Forton" de recubrimiento, que viene a demostrar la ineficacia de este sistema como refuerzo de los cementos.

(c) Consejo Superior de Investigaciones Científicas Licencia Creative Commons 3.0 España (by-nc)

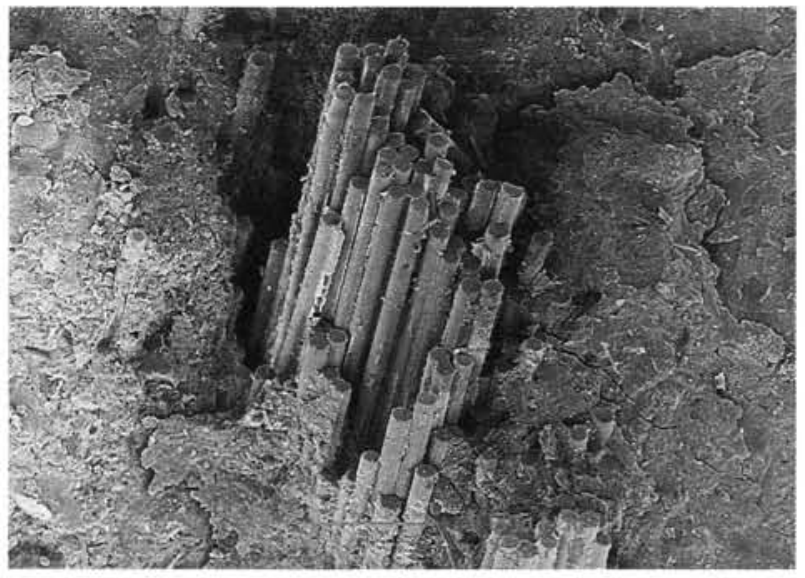

Fig. 20. Fractografía de una probeta de la placa ll ensayada tras 4 semanas de envejecimiento acelerado (magnificación: 400x).

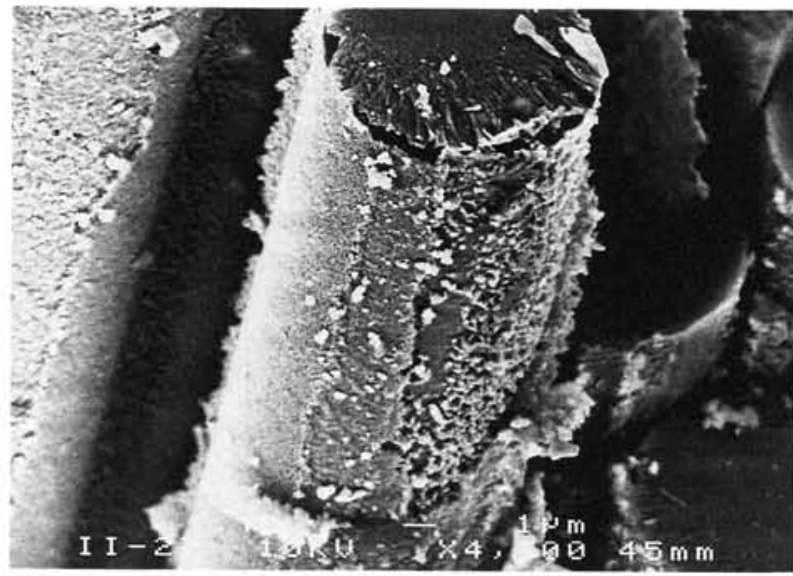

Fig. 21. Fractografía de una probeta de la placa ll ensayada tras 4 semanas de envejecimiento acelerado (magnificación: $7.000 x)$.

\section{CONCLUSIONES}

Se ha realizado un extenso programa experimental de ensayos mecánicos de probetas de GRC, fabricando placas de $10 \mathrm{~mm}$ de espesor, tanto por el método de premezclado, como por el de proyección.

Se han efectuado ensayos de tracción directa, siendo los primeros que se realizan en España sobre probetas de GRC.

Se confirma la importancia de la longitud de la fibra para obtener resistencias del GRC superiores a la tensión de inicio de la microfisuración. Las longitudes inferiores a unos $25 \mathrm{~mm}$ son ineficaces en este aspecto. http://informesdelaconstruccion.revistas.csic.es 
Se refleja la importancia del tipo de fibra utilizado sobre el comportamiento del GRC envejecido. Se apoya la afirmación de algunos autores acerca de la ineficacia del sistema "Forton" como medio de evitar la fragilización del GRC.

Se comprueba que el cemento reforzado con fibras $A R$ sufre asimismo un proceso de fragilización con la edad, si bien las probetas ensayadas tras 4 semanas de envejecimiento acelerado en agua a $50^{\circ} \mathrm{C}$ aún mantienen niveles aceptables de resistencia y ductilidad.
La adición de arena (eficaz como medio de reducir la retracción del GRC) produce una reducción de resistencia del GRC joven próxima a un $20 \%$ para la relación 1:1 utilizada en esta investigación.

Como complemento de la presente investigación, se han realizado estudios fractográficos de las probetas ensayadas a tracción simple. Es la primera vez que se realizan en España con GRC y han confirmado los distintos mecanismos de fractura para las diferentes placas ensayadas.

\section{AGRADECIMIENTOS}

M. L. Sánchez Paradela desea expresar su agradecimiento por la ayuda prestada a esta investigación a través del proyecto de investigación de CICYT, número PB87-0805 "Aplicaciones Arquitectónicas de los Materiales Compuestos y Aditivados", dirigido por D. Luis de Villanueva Domínguez, catedrático y director del Departamento de Construcción y Tecnologías Arquitectónicas de la E.T.S. de Arquitectura de Madrid.

Asimismo desea hacer mención de su agradecimiento a las siguientes personas:

- Al profesor Don Jesús Rodríguez Santiago, al faci- litar la utilización de la factoria de GRC de Dragados y Construcciones sita en Torrejón de Ardoz, para la fabricación de parte del material utilizado en la realización de este artículo.

- A Don Carlos Barba Solana por la ayuda ofrecida para la realización de las fractografías en el Servicio de Microscopia Electrónica de la Universidad Complutense de Madrid.

- A Don José Miguel Martínez, por su colaboración en diversas etapas del programa experimental.

\section{BIBLIOGRAFIA}

(1) Sánchez Paradela, M. L. (1990). "Modelización hasta rotura de los cementos reforzados con fibras de vidrio". Tesis Doctoral E.T.S. de Arquitectura. Madrid.

(2) Majumdar, A. J. y Nurse, R. W. "Glass Fibre Reinforced Cement". CP 79/74, 1974, pp. 77-94.

(3) Heavens, J. W.; Poesch, H. W. "Glass Fibre Reinforced Cement and its Commercial Exploitation". Fibre Reinforced Materials. Institute of Civil Engineers. Londres, 1977, pp. 125-127.

(4) Poesh, K. W. "Equipment for the Manufacture of Fibre Cement and Fibre Concrete Reinforced with Synthetic Fibres". Fourth Int. Conference on Durability of Building Materials and Components. Singapur 1987, pp. 287-294.
(5) Rodriguez, J. y Jordán, M. "The use of GRC in Spain and Algeria". Third Int. Symposium on Developments in Fibre Reinforced Cement and Concrete. Sheffield, Inglaterra, Julio 1986.

(6) Burr Bennet, W. "Is Mass Production of GRD Products the Next Step?". Prestressed Concrete Institute Journal. Vol. 33, No. 3, Mayo-Junio 1988.

(7) Shah, S. P.; Ludirdja, D.; Daniel, J. I. y Mobasher, B. "toughness-Durability of Glass Fiber Reinforced Concrete Systems". American Concrete Institute Materials Journal, Septiembre-Octubre 1988, pp. 352-360.

(8) Oakley, D. R.; Litherland, K. L. y Proctor, B. A. "The Development of a Method of Predicting the Weathering Behaviour of Glass Reinforced $\mathrm{Ce}$. 
ment Composites". Proceedings 2nd. Int. Conf. on Durability of Building Materials and Components, Septiembre 1981, National Bureau of Standards, pp. 225-228.

(9) CocKram, D. R.; Litherland, K. L.; Proctor, B. A. y Yale, B. "Assesing the Durability of Glass Compositions". Research and Development Laboratories of Pilkington Brothers PLC, Lancashire, Glastech, Ber. 1983, Vol. 56, pp. 644-649.

(10) Proctor, B. A.; Oakley, D. R. y Litherland, K. L. "Development in the Assesment and Performance of GRC over 10 Years". Composites (Guildford), Abril 1982, pp. 173-180.
(11) Proctor, B. A. "Past Development and Future Prospect for GRC Materials". Proceedings Int. Congress on Glass Fibre Reinforced Cement, París, Nov. 1981, The Glassfibre Reinforced Cement Association, pp. 50-67.

(12) Daniel, J. I. y Schultz, D. M. "Long-term Strength Durability of Glass Fibre Reinforced Concrete". RILEM Symposium FRC 86, Sheffield, Inglaterra, paper 7.4 .

(13) Shah, S.P.; Daniel, J. I. y Ludirdja, D. "Toughness of Glass Fiber Reinforced Concrete Panels Sub. jected to Accelerated Aging". Prestressed Con. crete Institute Journal, Sept.-Oct. 1987, pp. 352-360.

\section{publicaciones del ICCET / CSIC}

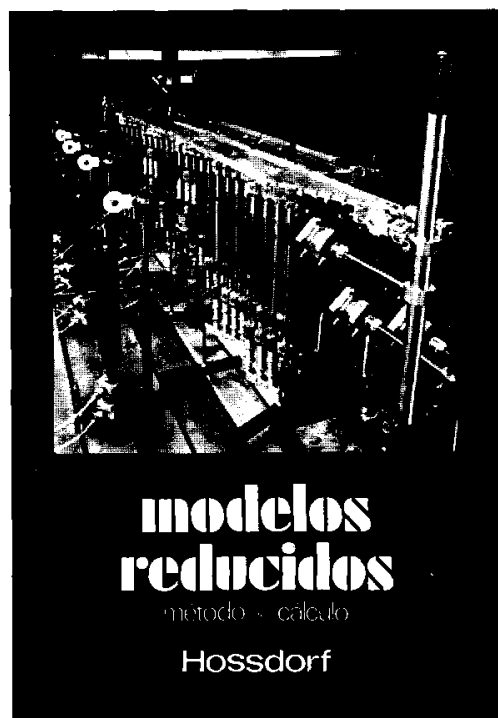

Modelos reducidos. Mátodo de cálculo

H. Hossdort, Ingeniero Civil

La técnica de los ensayos en modelos reducidos de estructuras sufre hoy dia una decisiva metamorfosis. Hasta hace poco era un medio mas bien de artesania, que no siempre era tomado en serio por los académicos teorizantes para comprender el comporta miento resistente de las estructuras complejas y al que se acudio las mas de las veces, como a un último remedio debido a sus indiscutibles insuficiencias. Sin embargo, en poco tiempo y gracias a su conexión con los ordenadores digitales, se ha transformado en un instrumento cientificamente valioso, que no puede quedar a un lado en la práctica diaria del Ingenjero Proyectista.

Un volumen encuadernado en cartoné plastificado con lomo de tela, de $17 \times 24 \mathrm{~cm}$, compuesto de 250 páginas, 158 figuras y fotografias.

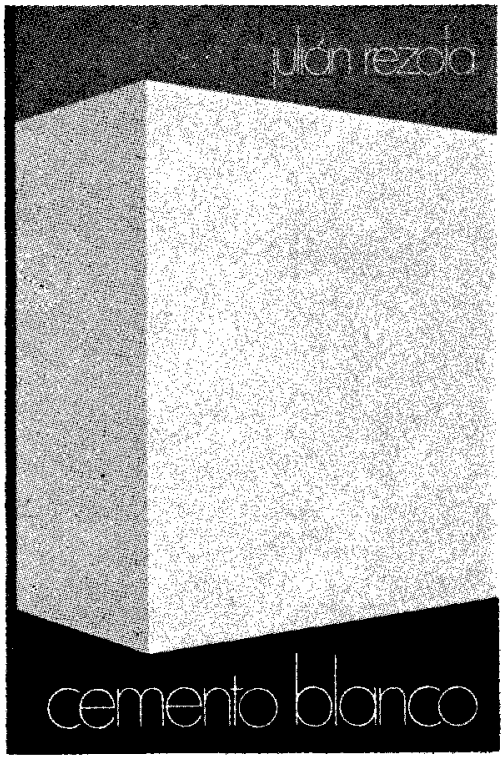

Cemento blanco

Julián Rezola

Ingeniero Químico Dipl. I. Q. S.

Sabido es que existe una extensa y documentada bibliografia sobre el cemento gris: en cambio, no puede decirse lo mismo acerca del cemento portland blanco, ya que los escritos existentes se refieren tan sólo a algunas peculiaridades que le distinguen de aquél.

El autor nos ofrece sus profundos conocimientos y su larga experiencia tanto en laboratorio como $y$ su larga exper

La parte descriptiva del libro se complementa con gráficos, diagramas y fotografías de gran utilidad destinados a conseguir la aplicación apropiada de este aglomerante.

Un volumen encuadernado en cartoné policerado, de $17,4 \times 24,3 \mathrm{~cm}$, compuesto de 395 páginas, numerosas figuras, tablas y ábacos.

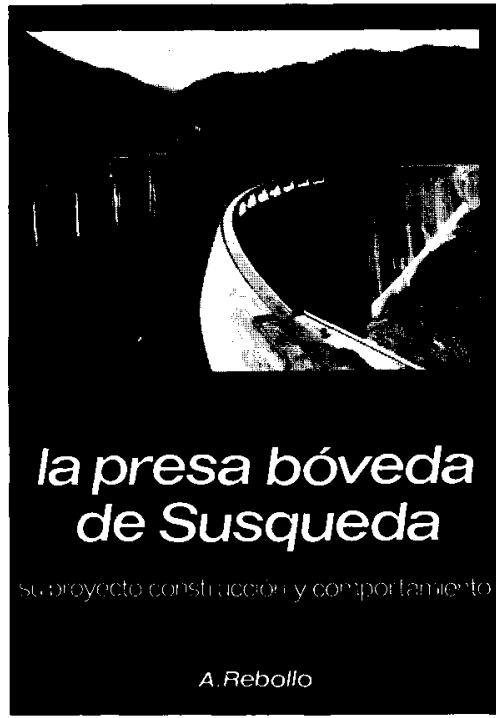

La presa bóveda de Susqueda

A. Rebollo,

Dr. Ingeniero de Caminos

El esfuerzo del constructor de presas se sitủa, por su pretension de perennidad a contracorriente de las tendencias de la civilización actual caracte rizada por to fungible. Pueden evocarse las 10.000 grandes presas en funcionamiento o en construccion que están envejeciendo y reclaman los cuidados gerontológicos para mantener $y$ perfeccionar su servicio y garantizar su inalienable pretensión de perennidad. En la medida en que todas nuevas obras, grandes o pequeñas, son portadoras de riesgos ecologicos $y$, a veces, catastroficos, aue aumentan con el envejecimiento, la gerontologia de las presas es todo un emplazo. La acción adelantada de Arturo Rebolio en este terreno marca un camino a seguir para todos los que aman su propia obra con la devoción paternal que él ha puesto en Susqueda.

Un volumen encuadernado en cartoné plastificado con lomo de tela, de $18 \times 24,5 \mathrm{~cm}$, compuesto de 408 paginas, 330 figuras $y$ folografias $r$ 39 tablas. 